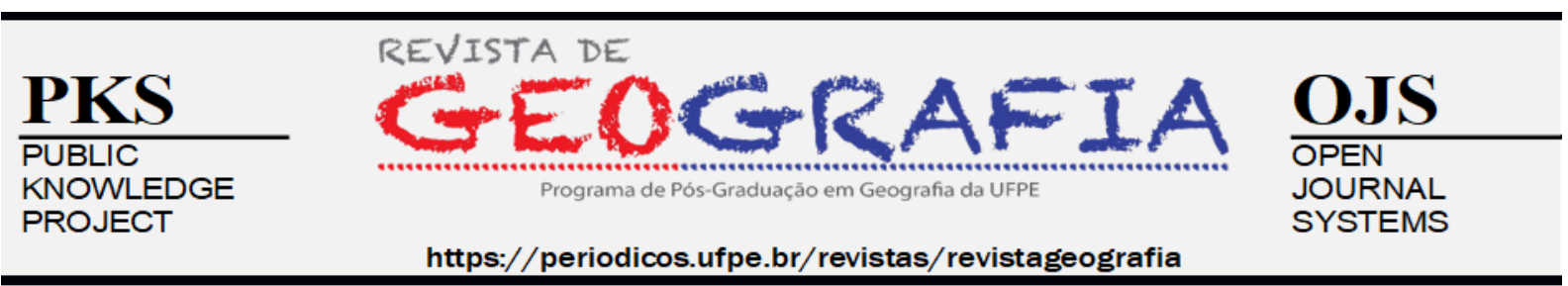

\title{
CIDADES DO AGRONEGÓCIO: A RELAÇÃO ENTRE CAMPO E CIDADE EM LUCAS DO RIO VERDE - MT
}

\author{
Gleice Kelly de Souza Pacheco ${ }^{1}$
}

${ }^{1}$ Universidade Federal do Rio de Janeiro, E-mail: gleice.spacheco@gmail.com, ORCID: http://orcid.org/00000002-7296-105X

Artigo recebido em 01/08/2021 e aceito em 18/09/2021

\begin{abstract}
RESUMO
A inserção do Brasil no mercado internacional de commodities, no século XXI, esteve fortemente associada à exploração de seus recursos naturais (DELGADO, 2012). Nesse contexto, o cerrado de Mato Grosso torna-se o epicentro dos investimentos do capital relacionado à produção de grãos, com expansão intensificada da produção de soja e milho na BR-163 mato-grossense, utilizando elevado nível técnico, científico e informacional. É importante destacar que o cultivo da soja no cerrado exige a presença de cidades concentradoras de serviços especializados, financeiros e científicos, exigidos pela modernização agrícola dessa commodity. Ou seja, é na cidade que se decide e coordena a produção agrícola. No município selecionado como área de estudo, Lucas do Rio Verde, em 2005, com a chegada da Sadia, a cadeia de carnes se associou à de grãos, atraindo indústrias especializadas, resultando em mudanças na estrutura urbana. Nesse sentido, este trabalho tem como objetivo analisar as mudanças detectadas no espaço urbano a partir das transformações do campo, relacionadas aos processos geradores de novas formas, funções e estruturas.
\end{abstract}

Palavras-chave: Agronegócio; Reestruturação; Cidade Média; Agricultura.

\section{AGRIBUSINESS CITIES: THE RELATIONSHIP BETWEEN COUNTRYSIDE AND CITY IN LUCAS DO RIO VERDE - MT}

\begin{abstract}
Brazil's insertion in the international commodities market in the 21 st century was strongly associated with the exploitation of its natural resources (DELGADO, 2012). In this context, the Cerrado of Mato Grosso becomes the epicenter of capital investments related to grain production, with intensified expansion of soybean and corn production on the BR-163 Mato Grosso, using a high technical, scientific and informational level. It is important to highlight that the cultivation of soy in the cerrado requires the presence of cities that concentrate specialized, financial and scientific services, required by the agricultural modernization of this commodity. In other words, it is in the city that agricultural production is decided and coordinated. In the municipality selected as the study area, Lucas do Rio Verde, in 2005,
\end{abstract}


with the arrival of Sadia, the meat chain became associated with the grain chain, attracting specialized industries, resulting in changes in the urban structure. In this sense, this work aims to analyze the changes detected in the urban space from the field transformations, related to the generating processes of new forms, functions and structures.

Keywords: Agribusiness; Restructuring; Middle City; Agriculture.

\title{
CIUDADES DE AGRONEGOCIOS: LA RELACIÓN ENTRE CAMPO Y CIUDAD EN LUCAS DO RIO VERDE - MT
}

\begin{abstract}
REANUDAR
La inserción de Brasil en el mercado internacional de commodities en el siglo XXI estuvo fuertemente asociada a la explotación de sus recursos naturales (DELGADO, 2012). En este contexto, el cerrado de Mato Grosso se convierte en el epicentro de las inversiones de capital relacionadas con la producción de granos, con una expansión intensificada de la producción de soja y maíz en la BR-163 Mato Grosso, utilizando un alto nivel técnico, científico e informativo. Es importante resaltar que el cultivo de soja en el cerrado requiere la presencia de ciudades que concentren servicios especializados, financieros y científicos, requeridos por la modernización agrícola de este commodity. Es decir, es en la ciudad donde se decide y coordina la producción agrícola. En el municipio seleccionado como área de estudio, Lucas do Rio Verde, en 2005, con la llegada de Sadia, la cadena cárnica se asoció con la cadena del grano, atrayendo industrias especializadas, resultando en cambios en la estructura urbana. En este sentido, este trabajo tiene como objetivo analizar los cambios detectados en el espacio urbano a partir de las transformaciones de campo, relacionados con los procesos de generación de nuevas formas, funciones y estructuras.
\end{abstract}

Palabras llave: Agronegocios; Reestructuración; Ciudad Media; Agricultura.

\section{INTRODUÇÃO}

A produção de grãos no cerrado do Centro-Oeste ocorre a partir dos anos 1970, com o surgimento de técnicas para correção do solo e melhoramento genético, dando continuidade à acumulação de capital em áreas antes consideradas desfavoráveis. Nesse contexto a produção de soja desenvolveu e se consolidou nos anos 1990.

A partir de 2000 tem-se a maior participação do Brasil no mercado internacional de commodities agrícolas, associadas à exploração de seus recursos naturais (DELGADO, 2012), conquistando assim cada vez mais importância na balança comercial brasileira, passando o cerrado, principalmente o de Mato Grosso, a se tornar o epicentro dos investimentos do capital relacionado às commodities dos grãos. A crescente participação da atividade primária na exportação foi responsável pela criação de novas urbanidades.

É importante destacar que esses espaços especializados agrícolas necessitavam de aporte 
urbano para concentrar suas necessidades relacionadas aos serviços especializados, vendas dos pacotes produtivos, armazenamento, bancos, enfim, de centros de serviço, financeirização e decisões. A produção de soja e milho sempre foi extremamente tecnificada, necessitando de aportes financeiros e científicos, além dos serviços especializados que a demanda do agronegócio exigia.

O urbano diferenciado e especializado em atender as demandas do agronegócio foi denominado por Denise Elias (2006) de "cidades do agronegócio", que são cidades que possuem suas formas, funções, processos e estruturas voltados para atender as demandas do agronegócio. Esses espaços surgiram simultaneamente aos espaços de produção, reformulando-se continuamente e se adequando às novas funções exigidas pela produção em cada fase.

Nos anos 2000, grandes empresários do ramo agrícola pensavam a necessidade de diversificar a produção, para que os grãos agregassem valor ao longo. A solução encontrada foi a implantação das cadeias agroindustriais de carnes (aves e suínos), com alto padrão técnico, que estariam integradas com a grande produção de grãos que, por sua vez, também seriam industrializados e transformados em ração, constituindo assim, a cadeia carne/grãos (BERNARDES, 2010). Empresas do ramo começaram a se instalar na região, com destaque para Sadia, que se instalou em 2005, em Lucas do Rio Verde (MT), área de estudo dessa pesquisa.

Com a implantação da cadeia de carnes, as cidades ganharam novas funções, com o desenvolvimento de um processo de industrialização associado às indústrias esmagadoras de soja, fábricas de ração, indústria de abate e industrialização da carne, entre outras. O processo de industrialização atraiu fortes contingentes migratórios para os novos postos de trabalho, ampliando ainda mais as funções dessas cidades. A infraestrutura também sofreu mudanças para atender às novas demandas da população: saneamento básico, serviços, educação, saúde, lazer e moradia popular para abrigar esses trabalhadores da indústria de carne. Com isso, novos processos foram se desenvolvendo, implantando-se novos fixos a partir de novas ações, dotados de outras funções, intensificando-se os fluxos.

Nesse sentido, este trabalho tem como objetivo analisar as mudanças detectadas no espaço urbano a partir das transformações do campo, relacionadas aos processos geradores de novas formas, funções e estruturas. Para dar conta da proposta do ponto de vista teórico, será utilizada a definição de Elias (2006) de cidades do agronegócio, as categorias de Santos (1992) 
forma, função, processo e estrutura, além do conceito circuitos espaciais da produção e círculos de cooperação de Castillo e Frederico (2010). Assim, o artigo será divido em três partes: na primeira será trabalhado a chegada da soja e a criação dessa cidade voltada para atender a demanda do campo. A segunda parte será trabalhado a chegada da indústria de carne e as alterações de forma e função ocorridas na cidade para atender uma nova demanda, e o por último, as mudanças ocorridas na cidade pela necessidade de grande força de trabalhado na indústria de carne, principalmente no abate.

\section{BREVE HISTÓRICO DA CHEGADA DA SOJA}

A ocupação da produção no campo, no Cerrado matogrossense, ocorre a partir dos anos 70, mas a expansão da fronteira agrícola inicia nos anos 1980, principalmente por uma conjuntura política e econômica de reorganização do território brasileiro.

A expansão dessa fronteira se torna efetiva por coincidir com o período de produção cada vez mais artificial e mais independente da condição do meio natural. Este período foi classificado como meio técnico-científico-informacional pelo geógrafo Milton Santos, e tem como principal característica a intensa fusão da técnica, da ciência e da informação. Essa fusão fez com que as barreiras naturais encontradas no Cerrado (clima quente e seco e solos ácidos) fossem superadas por meio da criação de novas técnicas de correção do solo e desenvolvimento genético para criação de sementes adaptadas a esse bioma, tornando possível "inventar a natureza" (Santos, 2009).

Junto com a expansão da fronteira agrícola, ocorre o início da colonização em Lucas do Rio Verde, que gerou intensificação no processo de urbanização daquele local, pois no período inicial, ao adquirirem um lote na área rural, o produtor também recebia como doação de um lote na área urbana. As escolas, hospitais, bancos, escritórios, assim como todos os serviços necessários para a produção de grãos, eram implantados nas áreas urbanas (GABRIG, 2017). As relações com o espaço urbano foram necessárias nessa região desde o início da produção agrícola. Segundo Frederico; 


\begin{abstract}
A especialização dos núcleos urbanos, provocada pelas demandas do campo moderno, transformou a antiga relação campo-cidade, baseada na regulação local e nos nexos de complementaridade. Na nova fase, a cidade tornou-se lócus principal da produção, pois é nesta que se concentram os principais serviços, produtos e agentes (trabalhadores agrícolas, produtores, consultores, empresas, bancos) necessários à produção. (p.7.2011).
\end{abstract}

A cidade se reorganiza para atender as demandas exigidas pela produção de grãos (milho e soja) que ocorrem nessa região. Para isso a cidade ofertará serviços para o campo moderno, Frederico (2011) destaca algumas, como: a revenda de insumos químicos, mecânicos e biológicos; a prestação de consultorias agronômicas, logística, financeira e de mercado; o beneficiamento e processamento agroindustrial dos grãos; o armazenamento e transporte dos grãos; o armazenamento e transporte de insumos e produtos agrícolas; o fornecimento do crédito de investimento e custeio (via bancos e empresas privadas); e a comercialização dos grãos (via corretores e tradings).

Dentre esses serviços o relacionado aos fluxos financeiros se torna o mais importante pois "a grande densidade tecnológica da agricultura moderna e a significativa parcela da produção destinada à exportação exigem a aquisição de vultosos créditos para investimento, custeio e comercialização por parte dos produtores e empresas privadas" (Frederico, 2011, p.9).

Segundo Elias "quanto mais moderna se torna a atividade agropecuária, mais urbana se apresenta sua regulação" (2006, p.16), dessa forma, temos a cidade como importante estrutura que concentra todos os serviços necessários para a produção desse novo campo altamente tecnificado e globalizado.

A modernidade no campo pode ser percebida pela utilização da agricultura de precisão, que se destaca como um dos principais fatores que garante a alta produtividade em Lucas do Rio Verde. Segundo dados de produção de grãos (soja e milho) PAM/IBGE de 2019, o rendimento médio chega a ser de $3.360 \mathrm{~kg} / \mathrm{ha}$, acima da média nacional.

Tabela 01: Área plantada, produção e rendimento médio de soja e milho em Lucas do Rio Verde. 


\begin{tabular}{c|c|c|c|c|c|c}
\hline Produção & \multicolumn{3}{|c|}{ Soja } & \multicolumn{3}{c}{ Milho } \\
\hline Ano & $\mathbf{2 0 0 0}$ & $\mathbf{2 0 1 0}$ & $\mathbf{2 0 1 9}$ & $\mathbf{2 0 0 0}$ & $\mathbf{2 0 1 0}$ & $\mathbf{2 0 1 9}$ \\
\hline $\begin{array}{c}\text { Área plantada } \\
\text { (HA) }\end{array}$ & 160.000 & 235.800 & 235.000 & 71.000 & 165.800 & 165.600 \\
\hline $\begin{array}{c}\text { Quantidade } \\
\text { produzida } \\
\text { (TON) }\end{array}$ & 528.000 & 756.648 & 789.600 & 215.414 & 794.016 & 1.041 .660 \\
\hline $\begin{array}{c}\text { Rendimento } \\
\text { médio (KG/HA) }\end{array}$ & 3.300 & 3.208 & 3.360 & 3.034 & 4.788 & 6.290 \\
\hline
\end{tabular}

Fonte: Sidra/IBGE. 2021

A cultura do milho, até recentemente, era considerada como secundária nos municípios da região concentrada, sendo plantada apenas após a colheita da soja. Porém sua produtividade foi se tornando expressiva. $\mathrm{O}$ aumento da quantidade produzida e do rendimento médio se justifica pela transformação industrial, que possui alto nível técnico, fazendo com que seja possível produzir grandes quantidades em áreas menores. As esmagadoras transformam o milho em farelo, destinado à produção de ração animal, além disso, destaca-se a recente entrada do setor energético na produção de etanol com base no produto. Esse aumento na área plantada e quantidade produzida está relacionado a chegada da indústria da carne no Mato Grosso, principalmente nos municípios cortados pela BR 163.

\section{A CHEGADA DA INDÚSTRIA DE CARNE EM LUCAS DO RIO VERDE}

A instalação de uma das unidades da Sadia e da cadeia produtiva de carnes foi pensada em um contexto de diversificação e verticalização da economia. Delgado (2012) explica que a retomada da atenção ao setor primário, ocorre devido a uma grave crise cambial no mundo em 1999, onde o governo federal decide elencar o setor primário-exportador como o responsável por controlar o saldo comercial brasileiro. Empresários do ramo passam a se interessar em atrair a indústria de carnes para a área concentrada da soja. O fato da região se apoiar principalmente na produção de grãos, gerava instabilidade e insegurança por se tratar de um mercado de 
commodities com fortes variações na bolsa de valores. Com o propósito de diversificar a produção e agregar valor à produção de grãos, a instalação da indústria da carne implicou em mudanças nas funções do urbano, atraindo novos fixos e fluxos, afetando a produtividade do campo. Segundo Gabrig

\footnotetext{
Por se tratar de uma relação de interdependente entre a cidade e o campo, devemos considerar que, com a transformação da cidade, o campo também precisou passar por alguns ajustes. No campo, foi necessário maior presença de tecnologia para intensificar a produção dos grãos, principalmente de soja e milho, e para gerar o aumento da escala de produção de aves e suínos, exigindo assim uma mão de obra qualificada, capaz de manipular equipamentos de precisão, e outros profissionais do campo moderno, como veterinários e agrônomos (p.111, 2016).
}

A cadeia de carnes demanda a intensificação da produção de grãos, logo o campo precisa produzir maiores quantidades de grãos. Quanto maior a especialização produtiva do campo e seu respectivo conteúdo em ciência e informação, maior será a urbanização e a inter-relação entre o campo e a cidade (Frederico, 2011). Assim, é função da cidade fornecer serviços de suporte ao campo, Gabrig (2016) destaca a revenda de insumos químicos, mecânicos e biológicos para a plantação, prestação de consultorias agronômica, logísticas, financeiras e de mercado, beneficiamento e processamento agroindustrial de grãos, armazenamento e transporte de insumos e produtos agrícolas, fornecimento de crédito de investimento e custeio (via bancos e empresas privadas), comercialização de grãos (via corretores e tradings), silos de armazenamento dos grãos, entre outros.

O urbano receberá, junto com seus novos fixos e fluxos, novas funções: industrializar e abater, funções essas que demandam de recursos em abundância como água, energia elétrica, grandes extensões para as instalações fabris, e força de trabalho numeroso com baixa qualificação para o abate e embalamento da carne. A escolha da Sadia em construir uma das unidades em Lucas do Rio Verde não foi ao acaso. Outros fatores que influenciaram na introdução das agroindústrias e dos frigoríficos nessas regiões relacionam-se à proximidade e à grande oferta da matéria-prima (soja e milho), que viabilizam a produção de ração a baixo custo. Existem 
ainda as vantagens concedidas pelos governos locais, como terrenos oferecidos para suas instalações, infraestrutura urbana e isenção de impostos por determinado período (Bernardes, 2010). Além dessas condições, temos também o fator político envolvido nessa decisão. A parceria público-privada é muito característica nos municípios de Mato Grosso, onde prefeitos e vices são proprietários de terras, donos de indústrias relacionadas à cadeia carne/grãos, etc. Assim, temos em 2008 a instalação da Sadia no município de Lucas do Rio Verde, que tem capacidade de abate de $500 \mathrm{mil}$ frangos/dia e de $10 \mathrm{mil} \mathrm{suínos/dia.} \mathrm{A} \mathrm{indústria} \mathrm{funciona} \mathrm{em} 3$ turnos (manhã, tarde e noite) 24 horas por dia.

De acordo com a Pesquisa Pecuária Municipal realizada pelo IBGE, a criação de galináceos em Lucas do Rio Verde, saltou de 78.936 cabeças em 2005 para 7.422 .908 cabeças em 2019 crescendo 9.304\%, enquanto a produção de suínos passou de 86.362 em 2005 para 133.129 em 2019, aumentando 54.2\%. O alto padrão técnico, organizado e integrado com a grande produção de grãos, os quais seriam industrializados e transformados em ração para os animais, constituindo assim a cadeia carne/grãos.(BERNARDES, 2011).

\section{MUDANÇAS NO URBANO: TRABALHO}

A chegada da BR Foods em Lucas do Rio Verde implicou o surgimento de novos empregos, fomentando o mercado de trabalho e aumentando a necessidade de mão de obra na cidade, tornando o primeiro fluxo impulsionado pela indústria de carne. Essa indústria necessita de um grande número de trabalhadores para o abate dos animais e para o embalamento, ambos os serviços realizados manualmente. As mudanças ocorreram com a chegada da cadeia de carnes em diversos âmbitos, como por exemplo do trabalho. A infraestrutura também sofreu mudanças para atender às novas demandas da população: saneamento básico, serviços, educação, saúde, lazer, etc. A reorganização dessa cidade está associada a mudanças a partir da criação de novos fixos, que geram novos fluxos e novas ações. Ao analisarmos as principais atividades econômicas em Lucas do Rio Verde e o percentual de 
absorção de mão de obra nos setores econômicos, observamos um crescimento significativo no anos de 2012 e 2019 no setor industrial - uma variação de 510\% entre esses dois anos, mostrando que o fluxo e a absorção de mão de obra ainda é grande. $\mathrm{O}$ aumento na indústria influenciou o aumento dos demais setores econômicos na cidade, como a construção, comércio e serviços.

O setor agropecuário, dentre os demais, não apresenta crescimento significativo como outro o que demonstra ser um setor com alto nível técnico, exigindo uma força de trabalho mais qualificada.

Tabela 2 - Número de trabalhadores nos setores de atividades econômicas - Lucas do Rio Verde

\begin{tabular}{c|c|c|c|c|c|c}
\hline Ano/Setores & Indústria & $\begin{array}{c}\text { Construção } \\
\text { Civil }\end{array}$ & Comércio & Serviços & Agropecuária & Total \\
\hline 2002 & 215 & 79 & 1.041 & 1.013 & 743 & 3.091 \\
\hline 2007 & 1.294 & 943 & 2.408 & 2.653 & 1.387 & 8.685 \\
\hline 2012 & 1.239 & 1.100 & 4.614 & 4.552 & 1.916 & 13.421 \\
\hline 2019 & 7.569 & 1.941 & 6.079 & 6.806 & 2.536 & 24.931 \\
\hline $\mathbf{2 0 1 2 - 2 0 1 9}$ & $\mathbf{5 1 0 \%}$ & $\mathbf{7 6 \%}$ & $\mathbf{3 1 \%}$ & $\mathbf{4 9 \%}$ & $\mathbf{3 2 \%}$ & $\mathbf{8 5 \%}$ \\
\hline
\end{tabular}

RAIS/CAGED, 2021.

A cadeia de carne, por não necessitar que a força de trabalho seja especializada, consegue absorver mais essa população em comparação a produção de soja, que é altamente tecnificada e especializada. Porém, a cidade de Lucas do Rio Verde não dispunha de tamanha quantidade de trabalhadores para ocupar os postos de trabalho, sendo necessário buscá-la em outros estados e regiões. Isso gerou um crescimento populacional expressivo, sendo uma das primeiras mudanças ocorridas no espaço urbano. 
Tabela 3 - Crescimento populacional de Lucas do Rio Verde

\begin{tabular}{c|c|c|c}
\hline Ano & Rural & Urbano & Total \\
\hline $\mathbf{1 9 9 1}$ & 2.361 & 4.332 & 6.693 \\
\hline $\mathbf{2 0 0 0}$ & 3.171 & 16.145 & 19.316 \\
\hline $\mathbf{2 0 1 0}$ & 3.101 & 42.455 & 45.556 \\
\hline $\mathbf{2 0 0 0 / 2 0 1 0}$ & $-2,25 \%$ & $162,9 \%$ & $135,8 \%$ \\
\hline
\end{tabular}

Fonte: Censo demográfico, IBGE 2019

Percebemos, ao analisarmos dados demográficos do Sidra/IBGE, que entre 2000 e 2010, em Lucas do Rio Verde, houve a duplicação da população que reside no município dessa cadeia carne/grãos, correspondendo a um total de 45.556 pessoas. Nesse contexto, a população urbana em 2010 foi a que mais cresceu e passou a corresponder a 93\% da população total. Dentre os municípios sob influência da BR-163, Lucas do Rio Verde foi o município que apresentou o maior crescimento com uma variação total de $135,8 \%$, onde a população urbana variou um total de $163 \%$, gerando a necessidade de mudanças na rede de serviços, de infraestrutura e no mundo do trabalho, em virtude da chegada de contingentes populacionais expressivos. Esse crescimento demográfico está atrelado justamente ao início das operações da indústria de carne da BR Foods.

Para a cidade absorver esse número de trabalhadores foi necessário uma construção de vilas residenciais para os trabalhadores da BR Foods, feita a partir de uma parceria entre município, Caixa Econômica Federal e Sadia no ano de 2009. Segundo a prefeitura de Lucas do Rio Verde, a vila abriga cerca de 6 mil pessoas, onde cerca de 1.530 lotes estão destinados aos trabalhadores da BRF. Esse terreno foi doado pela prefeitura, e as habitações foram construídas pela Sadia (na época ainda em processo de fusão com a Perdigão). Abaixo uma foto das casas. Sua configuração se assemelha com outros conjuntos habitacionais populares pelo país. São casas 
pequenas e simples, com lotes individuais com até dois quartos, uma sala e uma cozinha, não há muros entre elas.

\section{Imagem 1- Bairro operário da Sadia em Lucas do Rio Verde- MT.}

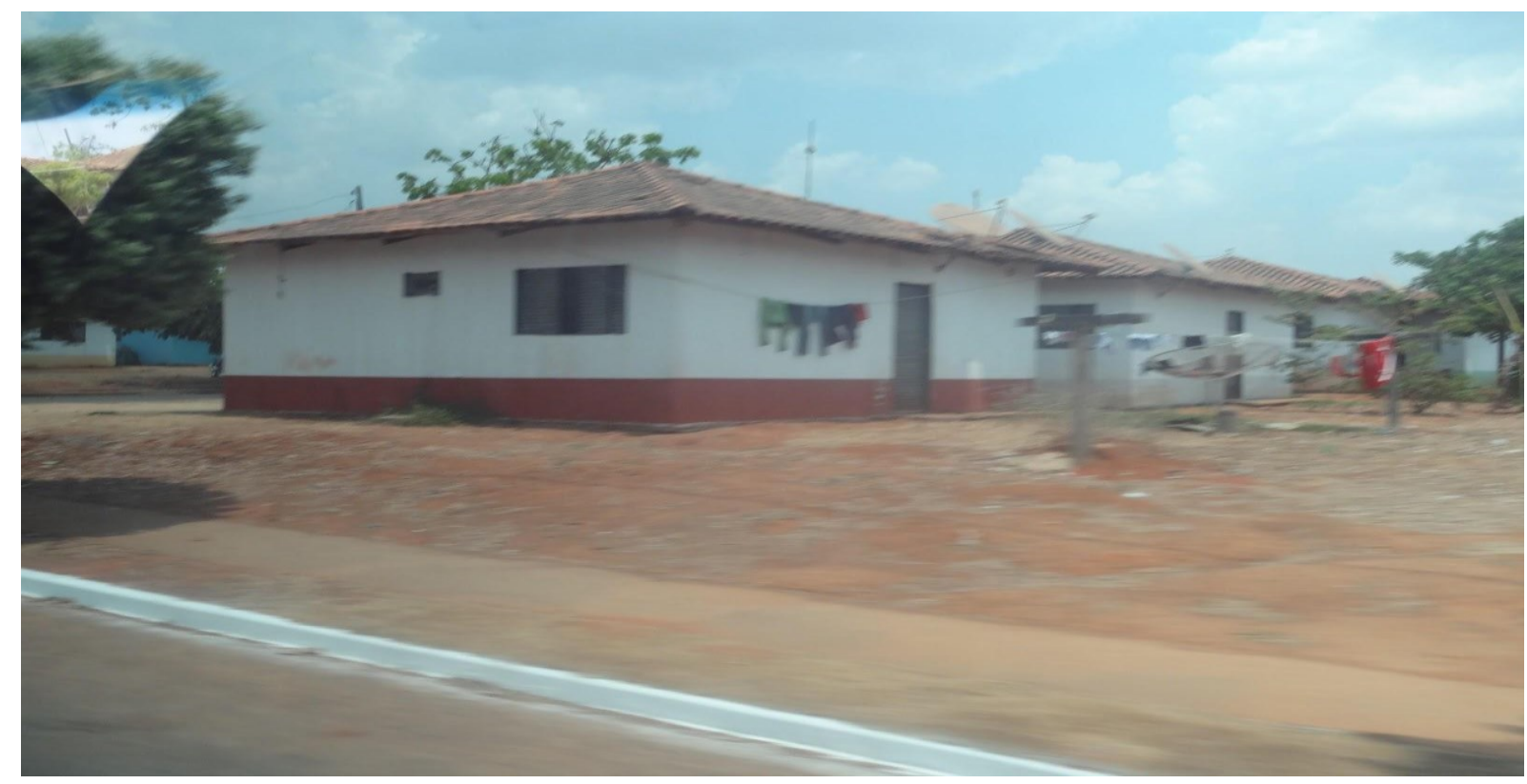

Fotografia: Gleice Pacheco, 2018.

O bairro foi construído em uma região afastada do centro de Lucas do Rio Verde, e sua localização já denuncia a intenção de segregar esses trabalhadores das áreas mais centrais da cidade. Nas cidades do agronegócio convivem dois tipos de migrantes: os que possuem condições de consumo e cuja infraestrutura é feita para seu usufruto; e os excluídos do consumo moderno, migrantes expulsos do campo pela modernização agrícola ou provenientes das áreas mais pobres do território brasileiro, que se alojam nas áreas periféricas e aumentam o número de desempregados, subempregados e trabalhadores informais (Frederico, 2011).

\section{CONSIDERAÇÕES FINAIS}

Em suma, nos anos 2000, ocorreram significativas mudanças na região concentrada da BR-163 mato-grossense com a chegada da indústria de carnes. Os municípios, antes voltados apenas 
para a produção dos grãos, ao receberem a cadeia de carne precisaram reorganizar a cidade e o campo para se ajustarem às suas exigências, agregando novos fixos, novas funções e gerando novos fluxos. A instalação de umas das unidades da BRF em Lucas do Rio Verde exemplifica, de forma geral, de que maneira essas alterações foram materializadas no espaço urbano, principalmente na questão da força de trabalho necessária para a indústria. Nesse sentido observa-se a produção de um tipo espaço urbano que visa atende aos interesses dos agentes modeladores, gerando e intensificando uma segregação espacial e social dos grupos de menor poder aquisitivo.

\section{REFERÊNCIAS BIBLIOGRÁFICAS}

BERNARDES, Júlia Adão. Novas fronteiras do capital no cerrado:cadeia carne/grão. Conferência proferida na $6^{\mathrm{a}}$ reunião Anual da SBPC: Cerrado, água, alimento e energia em julho 2011.

Cadeia carne/grãos: novas fronteiras do capital no cerrado da BR-163 matogrossense - Brasil. La planificación territorial y el urbanismo desde el diálogo y la participación. In: COLOQUIO INTERNACIONAL DE GEOCRÍTICA, 11., 2010, Buenos Aires. Anais... Buenos Aires: Universidad de Buenos Aires, 2010. BRASIL. MINISTÉRIO do Trabalho e Emprego - MTE. Relação Anual de Informações Sociais ação Anual de Informações Sociais

- RAIS. Brasília: disponível em <http://http://bi.mte.gov.br/bgcaged/> . Acessado em Set 2019. IBGE. SIDRA. Pesquisa Agrícola Municipal (PAM). disponível em $<$ https://sidra.ibge.gov.br/pesquisa/pam/tabelas $>$ Acessado em Out 2019. - Pesquisa Pesquisa Pecuária Municipal (PPM). disponível em

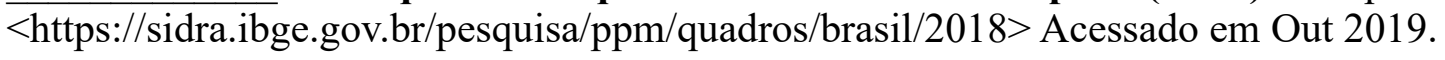

. Censo Demográfico de 2000 - 2010. 2010. Disponível em: https://sidra.ibge.gov.br/pesquisa/censo-demografico/demografico-2000/universo/. Acesso em: 8 de Jul. de 2019

CASTILLO, R. \& FREDERICO, S. Espaço geográfico, produção e movimento: uma reflexão sobre o conceito de circuito espacial produtivo. Sociedade \& Natureza. Uberlândia, 2010.

DELGADO, Guilherme Costa. Do capital financeiro na agricultura à economia do agronegócio: mudanças cíclicas em meio século (1965 - 2012). Rio Grande do Sul: UFRGS, 2012.

ELIAS, Denise. Globalização e fragmentação do espaço agrícola do Brasil. Revista Electrónica De Geografía Y Ciencias Sociales. Universidad de Barcelona. Vol. X, núm. 218 (03), 2006a. 
. Agronegócio e desigualdade sócio-espaciais. In: ELIAS, Denise; PEQUENO, Renato. (org.) Difusão do agronegócio e novas dinâmicas sócio-espaciais. Fortaleza: Banco do Nordeste do Brasil, 2006b.

GABRIG, Israella Pires Alves. A produção da cidade em áreas agrícolas especializadas: o caso de Lucas do Rio Verde - MT. 93 p. Dissertação (Mestrado em Geografia) - Programa de PósGraduação em Geografia, Universidade Federal do Rio de Janeiro, Rio de Janeiro, 2017.

- O Processo da Produção e os Agentes Modeladores das Cidades do Agronegócio. In: BERNARDES, Júlia Adão (Org.); BUHLER, Evé Anne (Org.); COSTA, Marcos Vinicius Velozo da (Org.) . As novas fronteiras do agronegócio. Transformações territoriais em Mato Grosso. Rio de Janeiro: Lamparina, 2016. Pg.101-121.

FREDERICO, Samuel. As cidades do agronegócio na fronteira agrícola moderna brasileira. Caderno Prudentino de Geografia, v. 1, n. 33, p. 5-23, 2011.

SANTOS, Milton. Espaço e Método. 3. ed. São Paulo: Nobel,1992.

A natureza do espaço: técnica e tempo - razão e emoção, São Paulo: EDUSP, 2009. 